\title{
CORRIGENDUM
}

\section{Connecting the time evolution of the turbulence interface to coherent structures - CORRIGENDUM}

\author{
Marius M. Neamtu-Halic, Dominik Krug, Jean-Paul Mollicone, \\ Maarten van Reeuwijk, George Haller and Markus Holzner \\ doi:10.1017/jfm.2020.414, Published online by Cambridge University Press, \\ 24 June 2020
}

The above mentioned article was submitted with incorrect author affiliations for George Haller and Markus Holzner.

This has since been rectified in the online PDF and HTML copies.

\section{REFERENCE}

Neamtu-Halic, M., Krug, D., Mollicone, J., Van Reeuwijk, M., Haller, G. \& Holzner, M. 2020 Connecting the time evolution of the turbulence interface to coherent structures. J. Fluid Mech. 898, A3. 